\title{
ФОРМИРОВАНИЕ ЛИЧНОСТИ СТУДЕНТА ПРИ ПОМОЩИ ИГРОВЫХ ВИДОВ СПОРТА (НА ПРИМЕРЕ ФУТБОЛА)
}

\section{FORMATION OF A STUDENT'S PERSONALITY WITH THE HELP OF PLAYING SPORTS (FOR EXAMPLE FOOTBALL)}

\author{
O. Antipov \\ E. Sukhanova \\ R. Gezha
}

Summary: As they grow older, young people develop their identity and become autonomous people. Young people do not share the experiences and memories of their elders. They develop their own ways of perceiving, evaluating, classifying, and distinguishing problems, as well as the codes, symbols, and language in which they can be expressed. Young people's responses to a changing world and their unique ways of explaining and communicating their experiences can help transform their cultures and prepare their societies for new challenges. Their dynamism can change some archaic and harmful aspects of their cultures that older generations consider unchangeable.

Sport is a universal element in all cultures. Sports are especially popular among young people. Another reason for the inclusion of sport is that sport provides young people with opportunities for social interaction through which they can develop the knowledge, skills and attitudes necessary for their full participation in civil society.

Culture and sport are human rights and are linked to various other human rights. They are also the grounds on which human rights are often violated and violated, including the rights of young people.

The article deals with the issues of physical education of students of higher educational institutions. The scientific foundations of the content of culture and a healthy lifestyle in the system of their physical education are highlighted. The main directions of the worldview orientations of the formation of a positive attitude to the active support of one's own health during life in the process of physical education of student youth are summarized on the example of game sports, and in particular football.

Keywords: student, physical education, healthy lifestyle, football, personality.
Антипов Олег Владимирович

к.б.н., дочент, Московская государственная академия ветеринарной медицины и биотехнологии имени им. К.И. Скрябина antipov_ov@bk.ru

Суханова Елена Юрьевна

к.б.н., доцент, Московская государственная академия ветеринарной медицины и биотехнологии имени им. К.И. Скрябина Гежа Роман Валерьевич

Преподаватель, Московская государственная академия ветеринарной медицины и биотехнологии имени им. К.И. Скрябина

Аннотация: По мере взросления молодые люди развивают свою идентичность и становятся автономными людьми. Молодые люди не делятся опытом и воспоминаниями старших. Они разрабатывают свои собственные способы восприятия, оценки, классификации и различения проблем, а также коды, символы и язык, на которых их можно выразить. Реакция молодых людей на изменяющийся мир и их уникальные способы объяснения и передачи своего опыта могут помочь преобразовать их культуры и подготовить их общества к решению новых задач. Их динамизм может изменить некоторые архаичные и вредные аспекты их культур, которые старшие поколения считают неизменными.

Спорт - это универсальный элемент во всех культурах. Спорт особенно популярен среди молодежи. Еще одна причина включения спорта заключается в том, что спорт предоставляет молодым людям возможности для социального взаимодействия, посредством которого они могут развивать знания, навыки и отношения, необходимые для их полноценного участия в гражданском обществе.

Культура и спорт являются правами человека и связаны с различными другими правами человека. Они также являются основаниями, по которым права человека часто нарушаются и нарушаются, в том числе права молодых людей.

В статье рассматриваются вопросы физического воспитания студентов высших учебных заведений. Выделены научные основы содержания культуры и здорового образа жизни в системе их физического воспитания. Обобщены основные направления мировоззренческих ориентаций формирования позитивного отношения к активной поддержке собственного здоровья в течение жизни в процессе физического воспитания студенческой молодежи на примере игровых видов спорта, а в частности футбола.

Ключевые слова: студент, физическое воспитание, здоровый образ жизни, футбол, личность.

менее важно, в молодежной культуре. Мы также можем говорить о культурном человеке, имея в виду человека с хорошими манерами и имеющего формальное образование в традициях литературы и искусства, или о культурном шоке: дезориентация и разочарование человека при знакомстве с незнакомой культурой. Ни одно из этих 
значений слова «культура» обычно не рассматривается министерствами культуры или аналогичными государственными органами.

Слово «культура» происходит от латинского «сultura», что означает «ухаживать, охранять, возделывать, обрабатывать». Впервые это слово начало появляться в переносном смысле «совершенствование через образование» примерно в 1500 году н.э., и только в середине 19 века это слово было связано с идеями о коллективных обычаях и образе жизни различных обществ. Именно это значение культуры, как унаследованных моделей общих значений и общего понимания мы рассматриваем в этой статье.

Ни одна культура не является однородной. Внутри каждой культуры можно выделить «субкультуры»: группы людей с особыми наборами практик и поведения, которые отличают их от более широкой культуры и от других субкультур. Культуру так же трудно определить, как и схватить; культуры постоянно развиваются и меняются. Если перефразировать Гераклита о том, что нельзя дважды войти в одну и ту же реку, то культура, в которой мы общаемся сегодня, отличается от той, в которой мы общались вчера. Тем не менее, в наших глазах и восприятии это действительно то же самое.

Комитет ООН по экономическим, социальным и культурным правам определяет культуру следующим образом:

«Культура [...] включает, среди прочего, образ жизни, язык, устную и письменную литературу, музыку и песни, невербальное общение, системы религии или убеждений, обряды. и церемонии, спорт и игры, методы производства или технологии, природная и искусственная среда, еда, одежда и жилье, а также искусство, обычаи и традиции, через которые отдельные лица, группы лиц и сообщества выражают свою человечность и то значение, которое они придают своему существованию и строят свое мировоззрение, представляющее их встречу с внешними силами, влияющими на их жизнь» [7].

Некоторые аспекты культуры очень заметны, например, как люди одеваются. Остальные аспекты в основном бессознательны, почти инстинктивны. Один из способов думать о культуре - использовать метафору айсберга. У айсберга есть видимая часть над ватерлинией и большая невидимая часть ниже. Точно так же в культуре есть некоторые аспекты, которые можно наблюдать и которые мы осознаем, а также другие аспекты, о которых можно только подозревать или вообразить и достичь которых можно только через диалог и самоанализ. Как корень айсберга намного больше его верхней части, так и большая часть культуры «невидима». Риск состоит в том, чтобы принять участие в целом. Сосредоточиваясь на том, что мы видим (и что мы, кажется, «понимаем»), мы рискуем упустить главное в людях, в людях.

Культура также является линзой, через которую мы рассматриваем и интерпретируем жизнь и общество. Культура передается от одного поколения к другому, при этом добавляются новые элементы и отбрасываются другие. Поскольку мы впитали так много преобладающей культуры с молоком нашей матери, очень трудно объективно рассматривать нашу собственную культуру; просто кажется нормальным и естественным, что наша собственная культура ощущается «правильной», а другие культуры с их различным образом мышления и поведения кажутся необычными - возможно, даже неправильными [1].

Определено, что рациональная организация здорового образа жизни студентов вузов является залогом сохранения здоровья. Знания в области физической культуры необходимы студентам для самостоятельной работы - двигательной активности, для повышения уровня соматического здоровья, для самосовершенствования [1]. Физкультура в высшей школе играет особую роль для определенного контингента, прежде всего для лиц с хроническими заболеваниями, с низким уровнем физической подготовленности, и особенно для студентов, не считающих физкультуру важной дисциплиной. Именно физическое воспитание студентов, их здоровье и здоровый образ жизни могут обеспечить здоровье генофонда страны, и большинство экспертов с этим согласны. Согласно многочисленным эмпирическим данным, в последнее время наблюдается снижение состояния здоровья студенческой молодежи. Установлено, что в высших учебных заведениях количество подготовительных и специальных медицинских групп увеличилось с 5,36\% на первом курсе до 14,46\% на третьем. Снижение уровня здоровья и физической работоспособности у студенческой молодежи является следствием значительной психоэмоциональной нагрузки, нарушений гигиенического обоснования режима дня и питания [5]. Являясь уникальной учебной дисциплиной, физическое воспитание интегрирует и взаимосвязывает решение основных задач воспитания, воспитания и реабилитации и является обязательным для обучения в высших учебных заведениях. В процессе обучения в университете студенты получают базовое (общее для всех) физическое воспитание. Физическое воспитание - это приобретение учащимися знаний по изучению биологических, психологических, социальных, мировоззренческих, физических, эстетических, поведенческих аспектов и резервных возможностей организма в процессе их физической деятельности. Это активный, творческий процесс и результат овладения системой физического воспитания, методическими и двигательными умениями, формирования в них ценностных установок и мировоззренческих ориентаций здорового образа жизни. Внедрение 
физического воспитания способствует воспитанию физической культуры личности, связанной с желанием, потребностью и способностью учащихся сохранять и совершенствовать свое здоровье посредством широкого спектра знаний о физическом воспитании, и на основе этого формируется мировоззрение и культура здорового образа жизни. В трудах специалистов в этой области физическое воспитание рассматривается как важный фактор здорового образа жизни, профилактики заболеваний, содержательной организации досуга и создания условий для всестороннего гармоничного развития личности студентов. Здоровый образ жизни является системообразующим фактором в процессе физического воспитания, обобщающим профессиональную культуру будущего специалиста и самосовершенствования личности, воспитания о своем здоровье, а также овладения всем арсеналом практических навыков и умений, обеспечивающих его сохранение и укрепление [6].

«Спорт» означает все формы физической активности, которые посредством случайного или организованного участия направлены на выражение или улучшение физического состояния и психического благополучия, формирование социальных отношений или достижение результатов в соревнованиях на всех уровнях.

Спорт, и особенно командные игры, являются важной частью нашей жизни, независимо от того, являемся ли мы зрителями или участниками. Для многих футбол это бесконечный источник разговоров, болельщики чувствуют глубокую близость со своей командой, а звездным игрокам присваивается статус героев. Современная мода на людей, желающих выглядеть хорошо, молодо, спортивно и здорово, проявляется в количестве открывающихся фитнес-клубов и количества издаваемых журналов о похудении, а в парках полно бегунов. Другие виды деятельности, связанные с умственными, а не физическими нагрузками, например шахматы, также считаются видами спорта. Существуют виды спорта на любой вкус и темперамент, поэтому спорт действительно может быть тесно связан с нашей идентичностью и культурой в какой-то момент нашей жизни.

Если мы глубже посмотрим на основную ценность и цель спорта и, в частности, футбола - в том числе и на игры студентов, - станет очевидным, что все виды спорта, развивались как средства обучения необходимым жизненным навыкам. вот почему спорт рассматривается как важная часть образовательной программы, как формальной, так и неформальной.

Психофизиология спорта - раздел спортивной психологии, изучающая взаимозависимость изменений психических и физиологических функций, происходящих в организме при занятиях спортом.
Специалистами определены основные задачи психологии спорта [2].

1. Изучение влияния спортивной деятельности, то есть тренировочных и соревновательных нагрузок на психику спортсменов.

2. Формирование состояния готовности спортсмена к деятельности.

3. Разработка психологических условий повышения эффективности подготовки спортсмена.

4. Разработка психологических основ предсоревновательной и соревновательной подготовки спортсменов, а также обоснование оптимальных условий после соревновательной деятельности, которые включают психологические средства восстановления и поддержания спортивной работоспособности.

5. Изучение механизмов активации резервных возможностей спортсменов.

6. Изучение социально-психологического жизнь спортивной команды для создания оптимальных межличностных отношений и формирование комфортного психологического климата в ней.

7. Разработка психологических условий гуманизации спортивной деятельности, содержание которой заключается в повышении содержательности спортивной деятельности, профилактике травматизма, переутомления, профессиональных заболеваний спортсменов, а также деформаций личности тренера и спортсмена.

8. Разработка системы психокоррекционных упражнений, которые бы снижали или устраняли негативные последствия тренировочных и соревновательных воздействий на психику спортсмена.

9. Создание условий для формирования психологических аспектов морально-патриотического воспитания спортсменов как патриотов Родины, которые представляют ее на соревнованиях различных уровней.

Психологические особенности соревновательной деятельности футболистов проистекают из сложного механизма сенсорных реакций: восприятия, мышления и двигательной активности [4]. С помощью восприятия, наблюдения и внимания футболист ориентируется в сложных условиях игры. Определенные двигательные действия осуществляются через мышление, память, представление и творческое воображение.

Футбол, а также другие виды спорта, игры, мероприятия, соревнования, основанные на системности, эмоциональности, перцептивно-интеллектуальных и эмоционально-волевых процессах или в условиях постоянно меняющихся обстоятельств, воспитывают в студентах определенные навыки и черты характера [2]:

- интуитивные навыки,

- социальные навыки, 
- умение жить вместе,

- умение овладевать спортивными движениями.

Одной из важнейших особенностей футболиста является способность точно ориентироваться в постоянно меняющихся сложных игровых условиях. Сенсорные процессы, основанные на примере изменения временных и пространственных параметров, определяющих отношения между партнерами, конкурентами и объектом игры, являются результатом одновременной работы нескольких спортсменов.

С помощью зрения осуществляется процесс восприятия игры. Зрительное восприятие позволяет увидеть как можно больше игроков, их положение и движение на поле. Умение отслеживать движения мяча, движения игрока, команды и соперника - важная черта очень талантливого футболиста, которую необходимо тренировать.

Для футболистов очень важно большое поле зрения, то есть развитие периферического зрения. Периферическое зрение - ключевой элемент тактического мышления игроков. Неразвитое периферическое зрение не позволяет игроку правильно воспринимать состояние игры, что ограничивает вариативность тактических движений и в целом влияет на стиль игры команды.

Помимо периферийного зрения футболиста, очень важен глубокий взгляд (точность зрения). Игровые операции, которые футболист выполняет в различных условиях. Для того чтобы определенный технический прием мог быть выполнен правильно и вовремя, расстояние между движущимися игроками и мячом должно быть точно определено.

Одним из основных принципов футбола является умение игрока разыгрывать мяч перед своим соперником. Спортсмену нужно хорошо развитое глубокое зрение. С точки зрения глубины, силы, точности, направления движения мяча, а также результатом становится конечная цель.

Экспериментально было установлено, что точность и объем видения игроком глубины игры напрямую зависят от тренировочного состояния. Так, точность глаз футболиста в спортивной форме в среднем на 35-40\% выше, чем в нетренированных ситуациях [3].

Для хорошо подготовленного футболиста характерно особое восприятие, основанное на высоком уровне владения мячом (так называемое «Чувство мяча»). Для этого необходимо развивать мышечное чувство и зрение, основанное на тонкой и точной дифференцировке раздражителей, которые передаются на различные анализаторы при работе с мячом.
«Чувство мяча», такое как «чувство времени» и «чувство пространства», развивается в течение длительного времени в процессе систематического развития. В связи с этим очень важна индивидуальная работа футболистов.

Внимание и основные характеристики психологической характеристики футболистов в соревновательном процессе - объем, интенсивность, длительность, распределение и изменение. Большее внимание позволит футбольной команде взаимодействовать с большой группой игроков (6-8 человек) и следить за перемещениями игроков соперника, узнавать их планы и предпринимать соответствующие ответные действия.

Чем выше спортивный уровень команд игроков, тем более напряженными и быстрыми становятся игровые позиции. Для того чтобы иметь возможность участвовать в таких ситуациях, игрок должен уметь уделять пристальное внимание, то есть концентрировать все усилия на определенных моментах игры. Чаще всего встречается в футболе, это отражение атаки в нанесении из обычных положений, а также штрафных ударов.

Игра в хоккей на траве длится 90 минут, в течение которых каждый игрок выполняет массу технико-тактических операций с мячом, а также различные движения на этапе отбора мяча. Поэтому важно поддерживать внимание игрока и мобилизовать усилия для эффективного выполнения игровой деятельности и взаимодействия с партнерами по команде во время игры. Чаще всего потеря внимания на 10 секунд (особенно на этапе отбора мяча) может привести к проигрышу игры.

Футболист, участвующий в игре, должен уметь отвлечь внимание от нескольких эпизодов, происходящих почти одновременно. Это скорость движения мяча, движения игроков и других лиц, время выполнения атакующих действий и т.д. В этом случае футболист создает алгоритм своей деятельности: сначала он решает выполнить определенное действие, затем второе, третье и т.д. Другими словами, игра отвлекает вас от действий в определенном логическом порядке.

Во время игры футболист должен не только уметь отвлекать его, но, прежде всего, уметь быстро привлекать внимание к различным моментам игры. Другими словами, футболист должен быстро перейти от фазы владения мячом к фазе приема и наоборот. В футболе это качество игрока - одно из самых ценных.

Реакция футболиста на каждую ситуацию является результатом избирательного внимания и оперативного мышления игрока и адаптируется к постоянным изменениям игровой ситуации. Соответствующие ситуации в ходе игры, технико-тактические операции с мячом 
или без мяча осуществляются с помощью тактического мышления, что является очень важной характеристикой игрока. В спортивных играх существует три уровня тактического мышления [2].

Первый уровень - это действия игрока, которые легко распознаются в наиболее часто повторяющихся ситуациях. Это условия численного превосходства $(2 \times 1,3 \times 2)$ и простых единоборств.

Второй уровень-это решение сложной комбинации игр, в которых игрок может выбрать наиболее подходящее решение на основе алгоритмов, которые он реализовал автоматически. Это означает, что в так называемых типичных случаях $(2 \times 2,3 \times 3$ и т.д.)

Основываясь на творческих характеристиках тактического мышления, третий высший уровень принятия решений имеет дело с новыми игровыми ситуациями, с которыми игрок не сталкивался.

Футболист должен обладать хорошо развитым тактическим мышлением, ему необходимо быстро и адекватно оценивать постоянно меняющиеся игровые ситуации, выбирать эффективное тактическое решение, умно планировать больше игр, прогнозировать действия соперников и скрывать свои намерения. Это требует выявления некоторых признаков тактического мышления [3]:

1. Эффективный характер мышления. Правильное выполнение действия в соответствии с состоянием игры. Это означает, что футболист должен немедленно оценить ситуацию, немедленно спланировать свои действия, выбрать оптимальный вариант действия и затем выполнить его. Продуктом тактического мышления в данном случае является характер и результат двигательного действия.

2. Наглядно-образное мышление. Эта характеристика тактического мышления требует высокого уровня развития пространственных и временных представлений в процессе групповых взаимодействий. Игроки с таким типом мышления не только успешно свяжутся со своими товарищами по команде, но и научатся их отслеживать.

3. Скорость мысли. Чем выше скорость мышления игрока, тем быстрее он оценивает обстановку игры и предпринимает соответствующие действия. Скорость мышления во многом обусловлена предыдущим опытом игрока, то есть знаниями и умениями. Опытный игрок обычно принимает более быстрые и точные решения на поле.

В целом активная соревновательная деятельность в футболе требует подготовки игроков с определенными сильными качествами, позволяющими им овладеть конкретными игровыми задачами. Эти проблемы включают в себя:

1. преодоление усталости из-за больших физических усилий;

2. способность выполнять большее ускорение, растяжение связок;

3. способность переносить боль;

4. может противостоять чужеродным стимулам, особенно поведению зрителя;

5. адаптироваться к различным условиям игры (полевые условия, плохие погодные условия и т. д.).

Спортивной команде свойственны признаки автономности, наличия общегрупповой цели, коллективизма, дифференцированности, структурности, численности.

Автономность-одна из основных особенностей спортивной команды, заключающаяся в сознательной обособленности от окружения, которое достигается благодаря ограничению количества ее членов, наличию специальных узкогрупповых целей, внутри-командной системы ценностей, правил, традиций, условностей и тому подобное.

Общегрупповая цель определяется формулировкой задач для достижения личных и общекомандных результатов.

Коллективизм - признак высшей формы развития спортивной команды, где групповая деятельность определяется и детерминируется социально важными общественными целями и ценностями.

Дифференцированность и структурность. Взаимодействие в процессе решения задач, стоящих перед командой, влечет за собой дифференциацию между ее членами как по выполняемым функциями и обязанностями, так и по личным контактам, то есть в середине команды возникают формальные (официальные) и неформальные (дружеские) группы. Однако групповая дифференциация еще не создает групповую структуру; этому способствуют связи и отношения между спортсменами и подгруппами спортсменов спортивной команды [5].

Итак, выделим основные черты характера, которые вырабатываются и укрепляются у студентов посредством игровых видов спорта, а в частности, футбола:

- студент беспокоится о развитии самодисциплины;

- студент не бросаете задание (даже очень трудное) до тех пор, пока не выполнит его;

- достигнув цели, студент ставит более высокую;

- студент настойчив даже перед лицом неудачи;

- у студента сильное желание добиться успеха;

- студент любит задачи, требующие больших усилий; 
- студент полностью отдаетесь выполняемой задаче.

Единственная потенциальная проблема такова: мотивация и стремление к успеху могут привести к тому, что студент будет тренироваться более интенсивно, чем нужно. Это может привести к повышенному состоянию тревоги, что, несомненно, отрицательно скажется на результатах.

\section{Выводы}

На наш взгляд, одним из путей, способных в определенной степени обеспечить решение проблемы здоровья студенческой молодежи, является формирование позитивного отношения к активной поддержке своего здоровья в течение всей жизни. В основе концепции формирования здорового образа жизни и культуры до- суга лежит формирование у студентов ценностных ориентаций на поддержание здоровья и культуры досуга.

На данный момент игра в футбол занимает первое место среди других видов спорта по количеству болельщиков, чем обусловлено поощрения всех молодых людей в развитии своих физических качеств в этом виде спорта. Игра в футбол предъявляет строгие требования к физическим, психологическим качествам, особенно к интеллектуальным. Сложные и разные условия игры, напряженность во время матча (особенно на чужом стадионе), проблемы в коммуникации напарников во время матча и после, переход в команду выше уровнем или лигой, все это выявляет психологические качества футболиста. От психологических качеств студента, который занимается футболом, зависят как его индивидуальные достижения, так и достижения его команды и молодежи в целом.

\section{ЛИТЕРАТУРА}

1. Агапова Н.Г. Социоцентристская и персональноцентристская парадигмы в образовании (культурологический анализ). Личность. Культура. Общество. 2008. Т.10. Вып.5-6(44-45). С. 265-271.

2. Алаторцев В.А. Готовность спортсмена ксоревнованиям: опыт психологического исследования. Москва: Физкультура и спорт, 1969. 76 с.

3. Бенгсбо Йенс Оборонительная тактика в футболе / Йенс Бенгсбо, Биргер Пейтерсон. - М.: Олимпийская литература, 2012. - 164 с.

4. Калянов Г.Н. Московская футбольная лига 1910-1922 / Г.Н. Калянов. - Москва: Машиностроение, 2014. - 300 с.

5. Теория и методика обучения предмету «физическая культура». Учебное пособие / под ред. Булгакова Н.Ж. М.: Юрайт, 2019. 304 с.

6. General comment №. 21 to art. 15, para. 1 (a), of the International Covenant on Economic, Social and Cultural Rights, Committee on Economic, Social and Cultural Rights, 2009

7. ООН и вопросы глобализации. «Культура и развитие» [Электронный ресурс]/Режим доступа: https://www.un.org/ru/development/globalization/culture_ development.shtml 